\title{
miR-122 targets an anti-apoptotic gene, $B c l-w$, in human hepatocellular carcinoma cell lines
}

\author{
Cliff Ji-Fan Lin ${ }^{\text {a,b }}$, Hong-Yi Gong ${ }^{\mathrm{b}}$, Hung-Chia Tseng ${ }^{\mathrm{b}, \mathrm{c}}$, Wei-Lun Wang ${ }^{\mathrm{b}, \mathrm{d}}$, Jen-Leih Wu ${ }^{\mathrm{a}, \mathrm{b}, *}$ \\ ${ }^{a}$ Graduate Institute of Life Sciences, National Defense Medical Center, Taipei, Taiwan \\ ${ }^{\mathrm{b}}$ Institute of Cellular and Organismic Biology, Academia Sinica, Nankang, Taipei, Taiwan \\ ${ }^{\mathrm{c}}$ Department of Life Sciences, National Taiwan Normal University, Taipei, Taiwan \\ ${ }^{\mathrm{d}}$ Institute of Fisheries Science, National Taiwan University, Taipei, Taiwan
}

\section{A R T I C L E I N F O}

\section{Article history:}

Received 21 July 2008

Available online 8 August 2008

\section{Keywords:}

miR-122

Bcl-w

Hepatocellular carcinoma

\begin{abstract}
A B S T R A C T
miR-122, a hepato-specific microRNA (miRNA), is frequently down-regulated in human hepatocellular carcinoma (HCC). In an effort to identify novel miR-122 targets, we performed an in silico analysis and detected a putative binding site in the $3^{\prime}$-untranslated region (3'-UTR) of Bcl-w, an anti-apoptotic Bcl-2 family member. In the HCC-derived cell lines, Hep3B and HepG2, we confirmed that miR-122 modulates $B c l-w$ expression by directly targeting binding site within the $3^{\prime}$-UTR. The cellular mRNA and protein levels of $B c l-w$ were repressed by elevated levels of $m i R-122$, which subsequently led to reduction of cell viability and activation of caspase-3. Thus, $B c l-w$ is a direct target of miR-122 that functions as an endogenous apoptosis regulator in these HCC-derived cell lines.
\end{abstract}

(c) 2008 Elsevier Inc. All rights reserved.
Hepatocellular carcinoma (HCC) is among the top 10 most prevalent cancers worldwide [1] and accounts for $80-90 \%$ of liver cancers [2]. Like other cancers, aberrant gene regulation features significantly in HCC. Using microarray analysis, several reports that profile the gene expression of HCC patients have identified numerous pathways (e.g., proliferation, cell cycle regulation, apoptosis, angiogenesis) that may be dysregulated during hepatocarcinogenesis [3]. In particular, the deregulated expression of proteins involved in cell cycle regulation, DNA repair [4], and apoptosis regulation [5] has been extensively described as a crucial event in the carcinogenetic process that leads to HCC development. Recently, a new class of small noncoding RNAs (miRNA) has been discovered [6] and implicated as playing a key role in development as well as in carcinogenesis [7]. By binding to the complementary sequences of their target mRNAs (mostly in the $3^{\prime}$-UTR), miRNAs are able to induce mRNA degradation or translational repression [8]. Dysregulation by miRNAs may affect previously known oncogenes or tumor-suppressor genes, thereby having implications on carcinogenesis.

miR-122 is a liver-specific miRNA that is expressed in the developing liver and at high levels in the adult liver, where it makes up $70 \%$ of all miRNAs $[9,10]$. The most well-known function of miR122 in the mammalian liver is to regulate lipid and cholesterol metabolism [11]. miR-122 down-regulation has been reported in

\footnotetext{
* Corresponding author. Address: Institute of Cellular and Organismic Biology, Academia Sinica, Nankang, Taipei 11529, Taiwan. Fax: +886 227824595.

E-mail address: jlwu@gate.sinica.edu.tw (J.-L. Wu).
}

rodent and human HCCs [12,13], suggesting that its function is associated with hepatocarcinogenesis. In HCC-derived cell lines, miR-122 directly targets cyclin G1 (CCNG1) by binding its 3'-UTR. An inverse correlation between miR-122 and CCNG1 exists in primary liver carcinoma, further emphasizing the importance of miR-122 in HCC pathogenesis [13]. In vertebrates, each miRNA has been predicted to target $\sim 200$ transcripts [14]. A search for other miR-122 regulatory targets that may be involved in the progression of HCC using online prediction algorithms has identified $B c l-w$, which harbors a putative $m i R-122$ binding site in its $3^{\prime}$-UTR. Bcl-w is an anti-apoptotic Bcl-2 family member [15]. Although mutations in anti-apoptotic Bcl-2 family genes ( $B c l-x L$, $M c l-1, B c l-w$, and a1) have not been identified as a cause of tumors, high expression levels of these proteins can contribute to carcinogenesis in cooperation with other proto-oncogenes [16]. The expression of $\mathrm{Bcl}-\mathrm{w}$ has been detected at relatively high levels in certain epithelium-derived tumor cell lines, such as colonic, cervical, and breast cancer cells [17]. In gastric adenocarcinomas, Bcl-w suppresses cancer cell death by blocking SAPK/JNK activation [18] and by promoting cell invasion by inducing metalloproteinase-2 (MMP-2) expression [19]. Bcl-w expression was modulated by Met/HGF receptor (c-met) in human colorectal cancers, and it inhibits apoptosis [20]. Moreover, Bcl-w was up-regulated in autoimmune hepatitis (AIH)-associated cirrhosis [21] and may play a role in hepatocarinogenesis.

In this study, we demonstrate that the expression level of cellular miR-122 can be elevated or inhibited by RNA polymerase IIbased miRNA-like siRNA expression vectors or a synthetic miRNA 
duplex, and subsequent experiments using this system provide evidence that miR-122 can directly repress the Bcl-w protein level by targeting binding sites in the $3^{\prime}$-UTR. Down-regulation of Bcl-w by $m i R-122$ results in a decrease in the Bcl-w/Bax ratio, ultimately leading to apoptosis in HCC-derived cell lines.

\section{Materials and methods}

Construction of miR-122 expression plasmids. Paired oligonucleotides including cohesive ends and a specific sequence for the sense and anti-sense $m i R-122$ strands were annealed and cloned into the corresponding ends created by BsmBI digestion in the pSM-155 vector (pSM-vector), a kind gift from Dr. Guangwei Du (Stony Brook University, NY, USA) [22]. This cloning step generates vectors that express sense (pSM-122_S) and anti-sense (pSM$122 \_$AS) $m i R-122$. The oligonucleotides are listed in Supplementary Table S1.

Cell culture and transfection. Hep3B, HepG2 and HeLa cells (ATCC Number: HB-8064, HB-8065, and CCL-2, respectively) were cultured in Dulbecco's Modified Eagle's Medium with 10\% fetal bovine serum and penicillin/streptomycin (Invitrogen). miR-122 duplex RNA (miR-122_D) and negative control RNA (miR-NC) were purchased from Integrated DNA Technologies (IDT). siRNAs that target Bcl-w (Bcl-w_siR; GenBank Accession No. NM_004050, region 3301-3321, 5'-CTCGGTCCTGCGATTATTAAT), and Bcl-xL (Bcl-xL_ siR; GenBank Accession No. NM_001191, region 642-662, 5'-GGC AGGCGACGAGTTTGAACT) were synthesized by Sigma according to a published report [23]. The day before transfection, cells were seeded in antibiotic-free medium. Plasmids and RNA duplexes transfection were carried out using Lipofectamine 2000 in accordance with the manufacturer's guidelines (Invitrogen). EGFP expression from pSM-122_S and pSM-122_AS was monitored $24 \mathrm{~h}$ post-transfection using an Olympus IX70 fluorescent microscope equipped with a BP450-480 pass excitation filter and a BA515 barrier emission filter. Photographs were taken with a CCD camera (Diagnostics Instruments) mounted to the microscope and processed using Spot software (Diagnostics Instruments).

miR-122 target prediction. Computer-based programs were used to predict potential $m i R-122$ targets. Using "has-miR-122" as a search term, we queried PicTar [14] (http://pictar.bio.nyu.edu/) and TargetScan 4.2 [24] (http://www.targetscan.org/). An miR-122/Bcl-w 3'-UTR duplex was predicted by RNAhybrid [25] (http://bibiserv.techfak.uni-bielefeld.de/rnahybrid/). Prediction algorithms and known miRNAs change over time, and the analysis included here is from May 2008.

Real-time quantitative RT-PCR. The expression level of miR-122 was measured in cells transfected with pSM-122_S, pSM-122_AS, pSM-Vector, miR-122_D, or miR-NC using the NCode ${ }^{\mathrm{TM}}$ miRNA First-Strand cDNA Synthesis Kit and NCode ${ }^{\mathrm{TM}}$ SYBR $^{\circledR}$ Green miRNA qRT-PCR Kit (Invitrogen) as described previously [26]. The level of U6 RNA was measured and used to normalize the relative abundance of $m i R-122$.

The expression levels of $C C N G 1, B c l-w$, and $B c l-x L$ were measured in cells 24 h post-transfection using High Capacity cDNA Reverse Transcription kit and Power SYBR Green PCR master Mix (Applied Biosystems) as described previously [27]. The primers used are listed in Supplementary Table S1.

Construction of $3^{\prime}-U T R$ reporter plasmids and luciferase assays. The 3'-UTRs of CCNG1 and Bcl-w were cloned downstream of the Renilla luciferase gene (Xhol/NotI sites) in the psiCheck-2 plasmid (Promega) and designated as psi-CCNG1 and psi-Bcl-w, respectively. (Primers are listed in Supplementary Table S1.) Hep3B cells were co-transfected with either miR-122 (pSM-122_S or miR-122_D), anti-sense miR-122 (pSM-122_AS) or negative controls (pSM-Vector or miR-NC) and target reporter plasmid using Lipofectamine
2000 (Invitrogen). The transfections and luciferase activity measurements were performed according to the manufacturer's instructions in the Invitrogen Lipofectamine 2000/Promega Dualluciferase kit. Relative protein levels were expressed as Renilla/firefly luciferase ratios.

Western blots. Hep3B and HepG2 cells were transfected in six-well plates with the indicated concentration of miR-NC, miR-122_D, Bcl-w_siR, or Bcl-xL_siR. After transfection, cells were cultured for $96 \mathrm{~h}$. Intermediate samples at 48 and $72 \mathrm{~h}$ were collected and analyzed by western blot to assess Bcl-w, Bax, and Bcl-xL expression as described [23]. Band signals were acquired in the linear range of the scanner using densitometric software (Quantity One, Bio-Rad). The ratio between the Bcl-w and the corresponding $\beta$-actin bands was used to quantitate $\mathrm{Bcl}-\mathrm{W}$ modulation by miR-122.

Cell viability and apoptosis assays. For cell viability assays, the cells were transfected with different quantities of miR-122_D as indicated. Seventy-two hours post-transfection, cell viability was measured by a colorimetric assay based on the cleavage of the tetrazolium salt WST-1 by mitochondrial dehydrogenases (cell proliferation reagent WST-1; Roche). To detect apoptosis, caspase-3 activity was assayed using the EnzChek Caspase-3 Assay Kit \#2 (Molecular Probes) according to the manufacturer's instructions. Measured fluorescence levels were normalized to the fluorescence levels of non-treated cell lysates.

Statistical analysis. Data are represented as means \pm SD of three independent experiments, each performed in triplicate. Statistical significance between treatment and control groups was analyzed using the Student's $t$ test $(P<0.05$ was regarded as significant and indicated with *).

\section{Results}

Expression of miR-122 in cells transfected with miR-122-expressing vectors and synthetic miR-122 duplex

In order to study the influence of $m i R-122$ on the expression of putative targets in HCC-derived cell lines, we changed the functional level of miR-122 in Hep3B and HepG2 cells as well as an unrelated HeLa cell line. To induce miR-122 expression in these cells, we first constructed sense and anti-sense miR-122 sequences into an miRNA-like siRNA vector [22]. This cloning step generated pSM-122_S and pSM-122_AS, vectors that express mature and anti-sense sequences of miR-122, respectively. After transfecting pSM-122_S and pSM-122_AS, the expression of a co-expressed fluorescent marker was monitored (Fig. 1A; only Hep3B was shown). Total RNA was reverse transcribed, and the relative amount of miR-122 RNA was measured by real-time qRT-PCR analysis. As expected, the expression level of $m i R-122$ was elevated by transfection of pSM-122_S in these cells (Fig. 1B). However, the decreased of miR-122 expression in response to transfection with pSM-122_AS was only observed in Hep3B cells, which may due to the relatively low level of endogenous miR-122 in HepG2 and HeLa cells $[13,28,29]$. In parallel, we evaluated the expression level of $m i R-122$ in these cells transfected with a synthesized miR-122 RNA duplex that has been functionally validated in vivo [30]. The intracellular level of $m i R-122$ was also increased by transfecting synthetic miRNA (Fig. 1B). These methods allowed us to control the cellular levels of $m i R-122$.

\section{miR-122 acts directly at the Bcl-w 3'-UTR}

Identifying miRNA-regulated gene targets is a necessary step to understand miRNA functions. miR-122 is the most abundantly expressed miRNA in human liver, and is known to regulate lipid and 

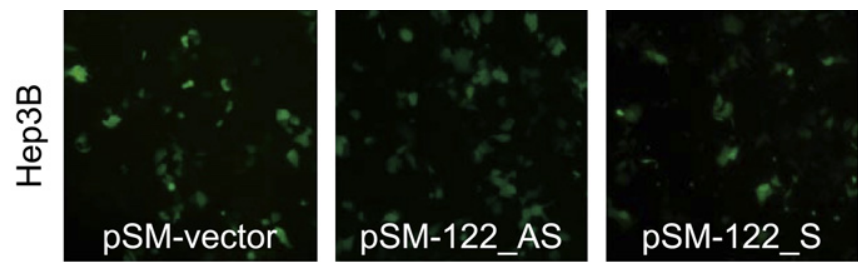

B

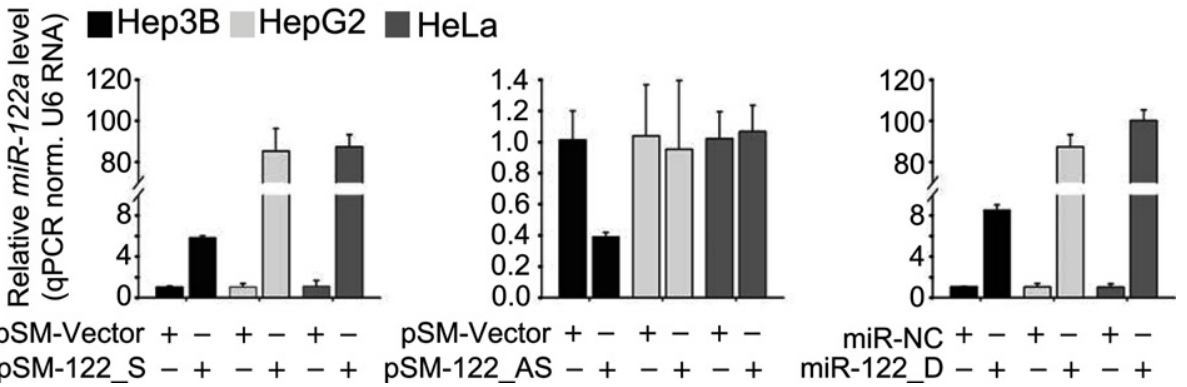

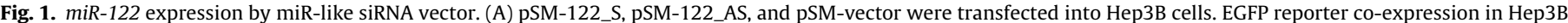

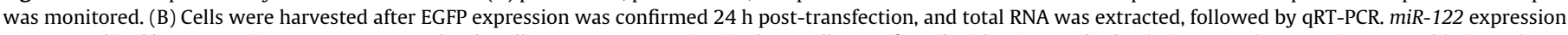

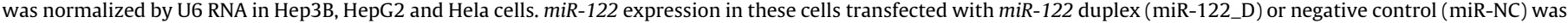
also measured. ${ }^{*} P<0.05$.

cholesterol metabolism [11]. However, the targets of miR-122 in hepatocarcinogenesis remain unclear. The only validated $m i R-122$ target involved in HCC is CCNG1 [13]. To identify putative miR122 targets that may contribute to tumorigenesis, an in silico strategy was employed. By querying PicTar [14] and TargetScan [24], an anti-apoptotic BCL2 family member, $B c l-w$, was identified in both programs as a putative $m i R-122$ target gene. The prediction results and score are listed in Fig. 2A; as a validated miR-122 target, CCNG1 is shown as a reference. Moreover, the PicTar prediction showed conserved binding sites on the 3'-UTR of Bcl-w across vertebrate species, including human, chimpanzee, dog, mouse, and rat (Fig. 2B). This observation suggests that miR-122 targeting to $\mathrm{Bcl}-\mathrm{w}$ may be evolutionarily conserved. The free energy of miR-122 binding to the $B c l-w$ targeting site was calculated using RNAhybrid (mfe:-17.5 kcal/mol), and the predicted structure is shown in Fig. 2C.

To substantiate that $m i R-122$ is a direct regulator of $B c l-w$, a 317-base pair fragment of the 3 '-UTR that contains the putative

\begin{tabular}{|c|c|c|c|c|}
\hline Predicted consequential pairing & of target region (top) and miRNA (bottom) & Seed Match & $\begin{array}{c}\text { TargetScan } \\
\text { Context score }\end{array}$ & $\begin{array}{l}\text { PicTar } \\
\text { Score }\end{array}$ \\
\hline $\begin{array}{r}\text { Position 832-839 of CCNG1 3' UTR } \\
\text { hsa-miR-122 }\end{array}$ & $\begin{array}{c}\text { 5, ... UUCAGACUAGAUUGA-ACACUCCA... } \\
\text { IIII IIIIIII } \\
3, \quad \text { UGUUUGUGGUACAGUGUGAGGU } \\
\end{array}$ & 8 mer & -0.38 & 3.03 \\
\hline $\begin{array}{r}\text { Position 1331-1337 of Bcl-w 3' UTR } \\
\text { hsa-miR-122 }\end{array}$ & $\begin{array}{c}\text { 5. } \ldots \text { GAGGAAGAAAUUAUU-CACUCCAG... } \\
\text { III IIIIII } \\
\text { 3, } \text { UGUUUGUGGUACAGUGUGAGGU }\end{array}$ & $7 \mathrm{mer}-1 \mathrm{~A}$ & -0.07 & 2.28 \\
\hline
\end{tabular}

BsBcl-w: 5' -CTTTTTCTTTTGA-GGAAGAAATTA-TTCACTCCAGATGCATGCCCTGAGCCAGA
PtBcl-w: 5' -СTTTTCTTTTGA-GGAAGAAATTA-TTCACTCCAGATGCATGCCCTGAGCCAGA
MmBcl-w: 5' -CCTTTTCTTTTGAGGGAGGAAATGA-TTCACTCCAAATGCATGCCCTGAGCCAGA
RnBcl-w: 5' -CTTTTTCTTTCGA-GGGAGGATCA-TTCACTCCAAACGCATGCCCTGAGCCAGA
CfBcl-w: 5' -CATTTTCTTTGA-GAGAGAAATTATTCACTCCAGATGTATGTCCTGAGCCAGA D

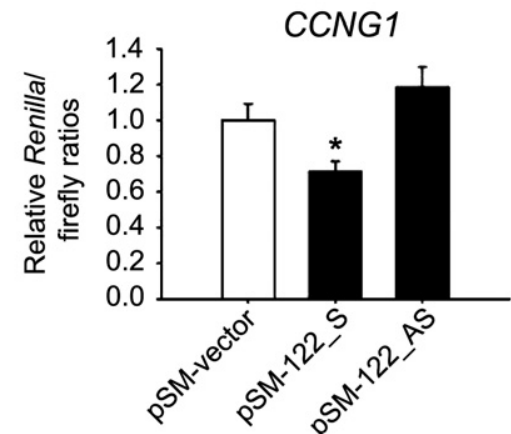

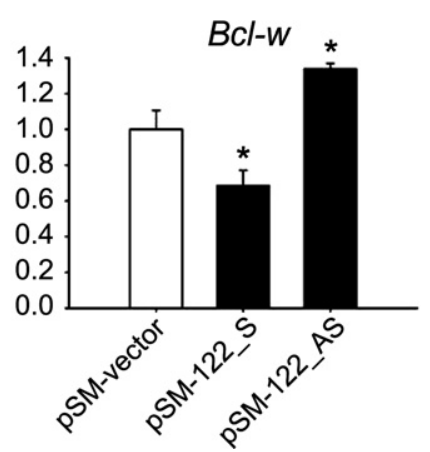

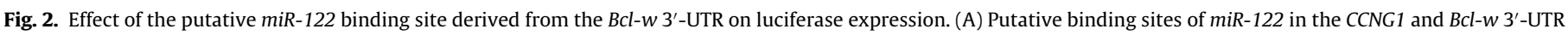

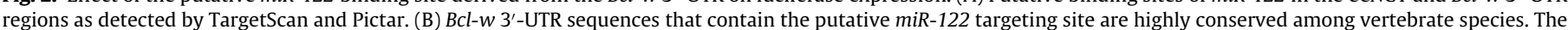

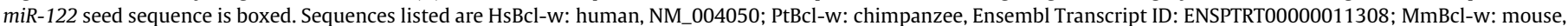

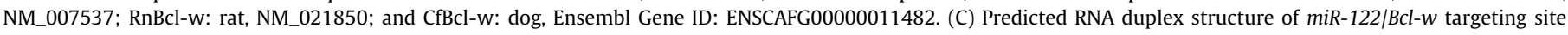

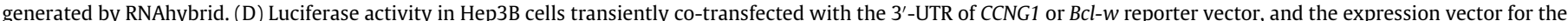

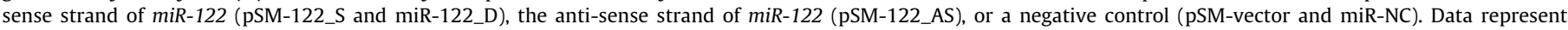
means \pm SD of three independent experiments, each performed in triplicate. ${ }^{*} P<0.05$. 
miR-122 binding site was cloned into the psiCHECK-2 reporter vector, downstream of the luciferase gene. The 3'-UTR of CCNG1 was cloned into the same vector as a positive control [13]. Upon cotransfection in Hep3B cells, the miR-122-expressing vector (pSM122_S) significantly repressed the expression of reporter construct, and anti-sense miR-122 (pSM-122_AS) increased the expression of the reporter construct relative to a vector-only control (pSM-vector) (Fig. 2D). Luciferase activity was again reduced with the cotransfection of the miR-122 duplex (miR-122_D). The repression of luciferase activity was more effective with miR-122_D than the miR-122-expression vector (Fig. 2D). This difference may occur because miR-122 duplexes were immediate substrates for RNA-induced silencing complex (RISC), whereas the vector-derived miR122 precursor required transcription and dicing to be processed into mature miRNAs.

Bcl-w expression is down-regulated by miR-122

To determine whether changing the functional level of cellular $m i R-122$ influenced the endogenous expression of $B c l-w$, cells were transfected with pSM-122_S and pSM-122_AS. Real-time qRT-PCR was performed at $24 \mathrm{~h}$ post-transfection. The mRNA expression levels of $\mathrm{Bcl}-\mathrm{W}$ were reduced to $77 \%, 81 \%$, and $42 \%$ in Hep3B, HepG2, and HeLa cells, respectively, when compared to the vector-only control (pSM-vector) (Fig. 3A). As a positive control, the mRNA expression levels of CCNG1 were reduced to 76\% in Hep3B cells (Fig. 3A). The mRNA expression level of CCNG1, however, was increased 1.3-fold upon transfection of pSM-122_AS, while no significant changes were observed in the level of $B c l-w$ in these cells, suggesting that additional mechanisms control $B c l-w$ expression. Bcl-w mRNA down-regulation was also reproduced when transfected with miR-122 duplex (miR-122_D) and the siRNA that targets $B c l-w$ (Bcl-w_siR) (Fig. 3A). We next examined the $B c l-w$ protein level in response to the elevated miR-122 level. Cells were transfected with miR-122_D, miR-NC, and Bcl-w_siR. The Bcl-w protein level was significantly reduced in cells transfected with miR-122 duplex (47\% and 53\%) and $B c l-w$ siRNA (76\% and $78 \%$ in Hep3B and HepG2, respectively) relative to miR-NC (Fig. 3B). Bcl$\mathrm{w}$ has been demonstrated to form a complex with pro-apoptotic Bax protein, and a reduced $\mathrm{Bcl}-\mathrm{w} / \mathrm{Bax}$ ratio has been shown to induce spermatogonial and spermatocyte apoptosis in the testis [31]. We therefore evaluated the Bax protein level in cells transfected with miR-122. The results showed no significant changes in the Bax protein level (Fig. 3B), and a reduced Bcl-w/Bax ratio (49.8\% and $52.7 \%$ in Hep3B and HepG2, respectively) was observed as expected. While the reduction of the $B c l-w$ mRNA level caused by miR-122_D and Bcl-w_siR was comparable (Fig. 3A), the reduction of $\mathrm{Bcl}-\mathrm{w}$ protein was more significant. This suggests that $m i R-122$ modulates $\mathrm{Bcl}-\mathrm{w}$ expression at the post-transcriptional level. To further confirm that miR-122 modulates the Bcl-2 system by specifically repressing $\mathrm{Bcl}-\mathrm{w}$ expression, we analyzed the expression of another anti-apoptotic Bcl-2 family member, Bcl-xL, in the cells with elevated miR-122 expression. There is no miR-122 targeting site detected in the $3^{\prime}-\mathrm{UTR}$ of $B c l-x L$. The results of this experiment show no significant change of Bcl-xL mRNA and protein levels (Fig. $3 \mathrm{~A}, \mathrm{~B})$. This suggests that $m i R-122$ specifically targets to $\mathrm{Bcl}-\mathrm{W}$ in these cells.

$B c l-w$ repression by miR -122 reduces cell viability and activates caspase-3 in the HCC-derived cell lines

The Bcl-w/Bax ratio was reduced in cells with an increased $m i R-122$ level. To investigate the biological importance of $\mathrm{Bcl}-\mathrm{w}$ as a target of $m i R-122$, we measured the cell viability and caspase-3 activity following transfection with different doses of miR-122_D. As shown in Fig. 4A and B, respectively, cell viability was decreased, and caspase-3 activity was increased, when elevating the functional level of cellular miR-122. To further confirm that
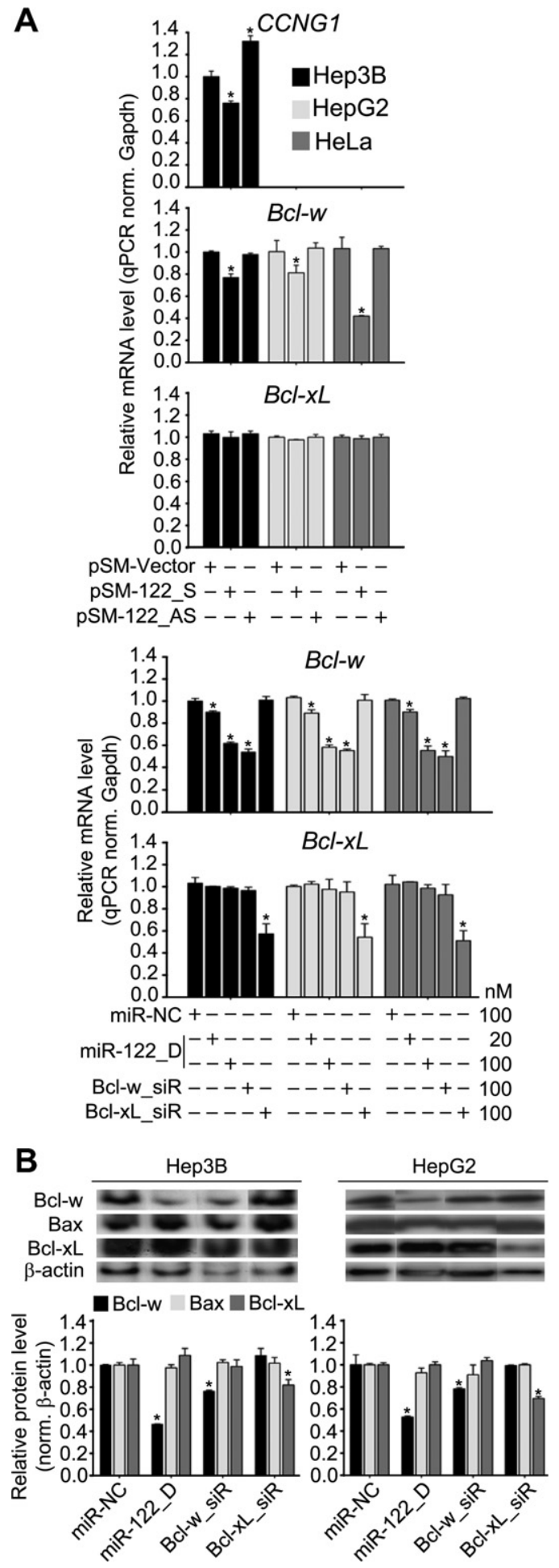

Fig. 3. $B c l-w$ expression is repressed by $m i R-122$. (A) The relative mRNA levels of $B c l-w$ and $B c l-x L$ were measured in cells transfected with pSM-122_S, pSM-122_AS, miR-122_D, Bcl-w_siR, and Bcl-xL_siR and compared to negative controls (pSMvector and miR-NC) by qRT-PCR $24 \mathrm{~h}$ post-transfection. As a validated miR-122 target, the mRNA level of CCNG1 was also measured in Hep3B cells as a positive control. (B) Western blot analysis of Bcl-w, Bax, and Bcl-xL protein level after miR122_D, Bcl-w_siR, or Bcl-xL_siR transfection. Cells were collected $72 \mathrm{~h}$ after transfection. All treatments had a final conc. of $100 \mathrm{nM}$. The relative $\mathrm{Bcl}-\mathrm{w}, \mathrm{Bax}$, and $\mathrm{Bcl}-\mathrm{xL}$ protein levels in each treatment were quantified as shown in the lower panel. ${ }^{*} P<0.05$. 

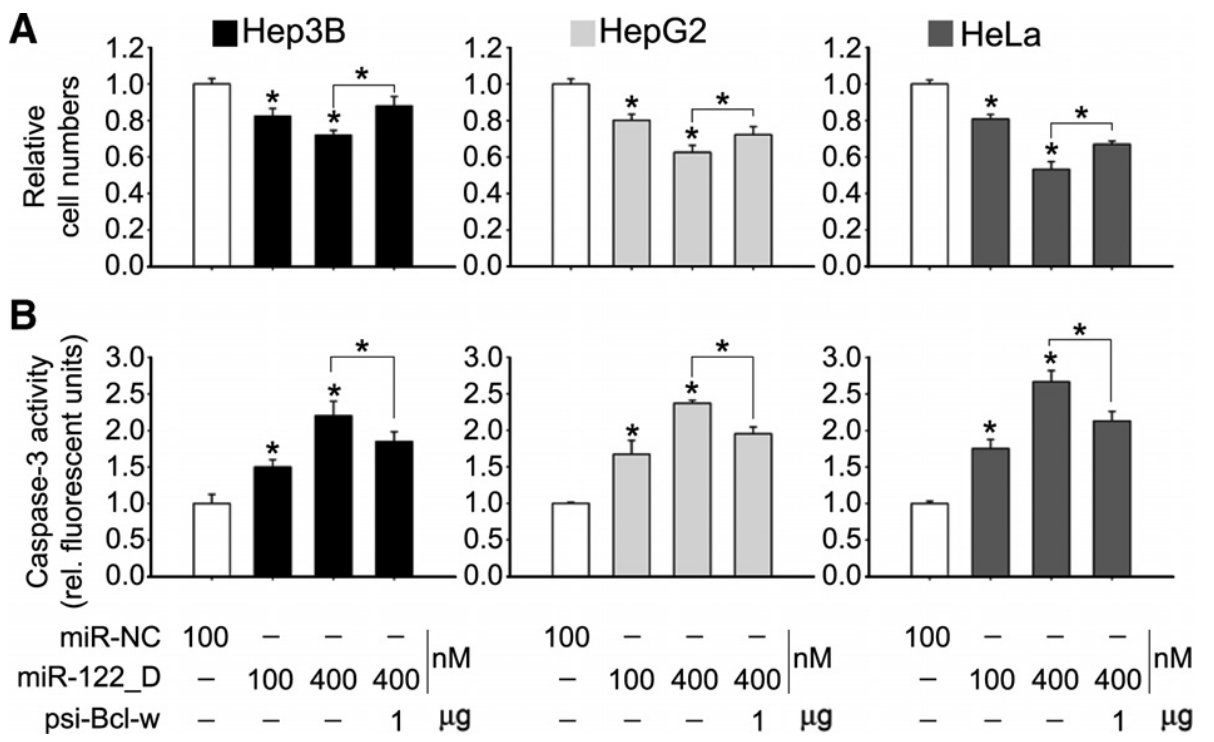

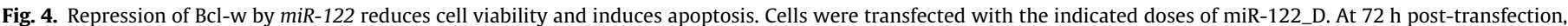
cell viability (A) and caspase-3 activity (B) were measured. psi-Bcl-w was co-transfected in the rescue experiments. ${ }^{*} P<0.05$.

$m i R-122$ is specifically responsible for the reduction of cell viability and the activation of caspase- 3 by targeting $B c l-w$, we co-transfected the $B c l-w$ 3'-UTR reporter construct, which harbors the miR-122 targeting site, to compete with endogenous Bcl-w transcripts. The results showed a partial rescue of cell numbers and decreased caspase-3 activity (Fig. 4A and B, respectively). These data confirm that $\mathrm{Bcl}-\mathrm{w}$ down-regulation by miR-122 triggers apoptosis and that the level of miR-122 expression is important for this mechanism.

\section{Discussion}

Although several miRNAs have been reported to be involved in controlling apoptosis and cancer formation [7,32], the only validated target gene of $m i R-122$, a liver-specific miRNA that is down-regulated in HCC, is CCNG1. Here, we report the modulating effects of $m i R-122$ on $B c l-w$ expression by directly targeting the 3'-UTR region of $B c l-w$ mRNA. miR-122 appears to inhibit Bcl-w at the post-transcriptional level in HCC-derived cell lines (Hep3B and HepG2) and a cervical carcinoma cell line (HeLa). The results of $B c l-w$ targeting by miR-122 may have implications in the pathogenesis of HCC. Our data suggest that decreased miR-122 expression helps cells evade cell death, a cardinal feature of cancer cells. Therefore, the reduced levels of miR-122 in HCC not only results in chromosomal instability through deregulation of CCNG1 but also enhances anti-apoptotic activity through an increase in the Bcl-w/Bax ratio. However, controversial miR-122 expression profile observations have been reported in HCC with different pathological causes. For example, replication of the hepatitis $C$ virus (HCV) was reported to depend on the status of miR-122 expression [29], and the expression level of miR-122 was not significantly decreased in HCV-associated HCC [28]. Further systematic research is required to clarify the role of deregulated miR-122 in HCC.

\section{Acknowledgments}

We thank Dr. Guangwei Du for kindly providing the pSM plasmids. This work was supported by Grant \# 96-2628-B-001-008 to Jen-Leih $\mathrm{Wu}$ from the National Science Council of Taiwan.

\section{Appendix A. Supplementary data}

Supplementary data associated with this article can be found, in the online version, at doi:10.1016/j.bbrc.2008.07.154.

\section{References}

[1] L.B. Seeff, J.H. Hoofnagle, Epidemiology of hepatocellular carcinoma in areas of low hepatitis B and hepatitis C endemicity, Oncogene 25 (2006) 37713777.

[2] A.M. Di Bisceglie, Issues in screening and surveillance for hepatocellular carcinoma, Gastroenterology 127 (2004) S104-S107.

[3] S.S. Thorgeirsson, J.S. Lee, J.W. Grisham, Functional genomics of hepatocellular carcinoma, Hepatology 43 (2006) S145-S150.

[4] L.R. Roberts, G.J. Gores, Hepatocellular carcinoma: molecular pathways and new therapeutic targets, Semin. Liver Dis. 25 (2005) 212-225.

[5] I. Fabregat, C. Roncero, M. Fernandez, Survival and apoptosis: a dysregulated balance in liver cancer, Liver Int. 27 (2007) 155-162.

[6] R.C. Lee, V. Ambros, An extensive class of small RNAs in Caenorhabditis elegans, Science 294 (2001) 862-864.

[7] K.O. Skaftnesmo, L. Prestegarden, D.R. Micklem, J.B. Lorens, MicroRNAs in tumorigenesis, Curr. Pharm. Biotechnol. 8 (2007) 320-325.

[8] O. Hobert, Gene regulation by transcription factors and microRNAs, Science 319 (2008) 1785-1786.

[9] J. Chang, E. Nicolas, D. Marks, C. Sander, A. Lerro, M.A. Buendia, C. Xu, W.S. Mason, T. Moloshok, R. Bort, K.S. Zaret, J.M. Taylor, miR-122, a mammalian liver-specific microRNA, is processed from hcr mRNA and may downregulate the high affinity cationic amino acid transporter CAT-1, RNA Biol. 1 (2004) $106-113$.

[10] M. Lagos-Quintana, R. Rauhut, W. Lendeckel, T. Tuschl, Identification of novel genes coding for small expressed RNAs, Science 294 (2001) 853-858.

[11] C. Esau, S. Davis, S.F. Murray, X.X. Yu, S.K. Pandey, M. Pear, L. Watts, S.L. Booten, M. Graham, R. McKay, A. Subramaniam, S. Propp, B.A. Lollo, S. Freier, C.F. Bennett, S. Bhanot, B.P. Monia, miR-122 regulation of lipid metabolism revealed by in vivo antisense targeting, Cell Metab. 3 (2006) 87-98.

[12] H. Kutay, S. Bai, J. Datta, T. Motiwala, I. Pogribny, W. Frankel, S.T. Jacob, K. Ghoshal, Downregulation of miR-122 in the rodent and human hepatocellular carcinomas, J. Cell. Biochem. 99 (2006) 671-678.

[13] L. Gramantieri, M. Ferracin, F. Fornari, A. Veronese, S. Sabbioni, C.G. Liu, G.A. Calin, C. Giovannini, E. Ferrazzi, G.L. Grazi, C.M. Croce, L. Bolondi, M. Negrini, Cyclin G1 is a target of miR-122a, a microRNA frequently down-regulated in human hepatocellular carcinoma, Cancer Res. 67 (2007) 6092-6099.

[14] A. Krek, D. Grun, M.N. Poy, R. Wolf, L. Rosenberg, E.J. Epstein, P. MacMenamin, I. da Piedade, K.C. Gunsalus, M. Stoffel, N. Rajewsky, Combinatorial microRNA target predictions, Nat. Genet. 37 (2005) 495-500.

[15] L. Gibson, S.P. Holmgreen, D.C. Huang, O. Bernard, N.G. Copeland, N.A. Jenkins, G.R. Sutherland, E. Baker, J.M. Adams, S. Cory, bcl-w, a novel member of the bcl-2 family, promotes cell survival, Oncogene 13 (1996) 665-675.

[16] B. Zhivotovsky, S. Orrenius, Carcinogenesis and apoptosis: paradigms and paradoxes, Carcinogenesis 27 (2006) 1939-1945. 
[17] L.A. O’Reilly, C. Print, G. Hausmann, K. Moriishi, S. Cory, D.C. Huang, A. Strasser, Tissue expression and subcellular localization of the pro-survival molecule Bcl-w, Cell Death Differ. 8 (2001) 486-494.

[18] H.W. Lee, S.S. Lee, S.J. Lee, H.D. Um, Bcl-w is expressed in a majority of infiltrative gastric adenocarcinomas and suppresses the cancer cell death by blocking stress-activated protein kinase/c-Jun NH2-terminal kinase activation, Cancer Res. 63 (2003) 1093-1100.

[19] I.H. Bae, M.J. Park, S.H. Yoon, S.W. Kang, S.S. Lee, K.M. Choi, H.D. Um, Bcl-w promotes gastric cancer cell invasion by inducing matrix metalloproteinase-2 expression via phosphoinositide 3-kinase, Akt, and Sp1, Cancer Res. 66 (2006) 4991-4995.

[20] S. Kitamura, S. Kondo, Y. Shinomura, S. Kanayama, Y. Miyazaki, T. Kiyohara, S. Hiraoka, Y. Matsuzawa, Met/HGF receptor modulates bcl-w expression and inhibits apoptosis in human colorectal cancers, Br. J. Cancer 83 (2000) 668673.

[21] N.A. Shackel, P.H. McGuinness, C.A. Abbott, M.D. Gorrell, G.W. McCaughan, Insights into the pathobiology of hepatitis C virus-associated cirrhosis: analysis of intrahepatic differential gene expression, Am. J. Pathol. 160 (2002) 641-654.

[22] G. Du, J. Yonekubo, Y. Zeng, M. Osisami, M.A. Frohman, Design of expression vectors for RNA interference based on miRNAs and RNA splicing, FEBS J. 273 (2006) 5421-5427.

[23] N.L. Tran, W.S. McDonough, B.A. Savitch, T.F. Sawyer, J.A. Winkles, M.E. Berens, The tumor necrosis factor-like weak inducer of apoptosis (TWEAK)-fibroblast growth factor-inducible 14 (Fn14) signaling system regulates glioma cell survival via NFkappaB pathway activation and BCL-XL/BCL-W expression, J. Biol. Chem. 280 (2005) 3483-3492.
24] A. Grimson, K.K. Farh, W.K. Johnston, P. Garrett-Engele, L.P. Lim, D.P. Bartel, MicroRNA targeting specificity in mammals: determinants beyond seed pairing, Mol. Cell 27 (2007) 91-105.

25] M. Rehmsmeier, P. Steffen, M. Hochsmann, R. Giegerich, Fast and effective prediction of microRNA/target duplexes, RNA 10 (2004) 1507-1517.

[26] L.T. Bemis, R. Chen, C.M. Amato, E.H. Classen, S.E. Robinson, D.G. Coffey, P.F. Erickson, Y.G. Shellman, W.A. Robinson, MicroRNA-137 targets microphthalmia-associated transcription factor in melanoma cell lines, Cancer Res. 68 (2008) 1362-1368.

[27] M.C. Hu, H.Y. Gong, G.H. Lin, S.Y. Hu, M.H. Chen, S.J. Huang, C.F. Liao, J.L. Wu, $\mathrm{XBP}-1$, a key regulator of unfolded protein response, activates transcription of IGF1 and Akt phosphorylation in zebrafish embryonic cell line, Biochem. Biophys. Res. Commun. 359 (2007) 778-783.

[28] H. Varnholt, U. Drebber, F. Schulze, I. Wedemeyer, P. Schirmacher, H.P. Dienes, M. Odenthal, MicroRNA gene expression profile of hepatitis C virus-associated hepatocellular carcinoma, Hepatology 47 (2008) 1223-1232.

[29] C.L. Jopling, M. Yi, A.M. Lancaster, S.M. Lemon, P. Sarnow, Modulation of hepatitis C virus RNA abundance by a liver-specific MicroRNA, Science 309 (2005) 1577-1581.

[30] AJ. Giraldez, Y. Mishima, J. Rihel, RJ. Grocock, S. Van Dongen, K. Inoue, A.J. Enright, A.F. Schier, Zebrafish MiR-430 promotes deadenylation and clearance of maternal mRNAs, Science 312 (2006) 75-79.

[31] W. Yan, M. Samson, B. Jegou, J. Toppari, Bcl-w forms complexes with Bax and Bak, and elevated ratios of $\mathrm{Bax} / \mathrm{Bcl}-\mathrm{W}$ and $\mathrm{Bak} / \mathrm{Bcl}-\mathrm{W}$ correspond to spermatogonial and spermatocyte apoptosis in the testis, Mol. Endocrinol. 14 (2000) 682-699.

[32] M. Jovanovic, M.O. Hengartner, miRNAs and apoptosis: RNAs to die for Oncogene 25 (2006) 6176-6187. 